\title{
Respostas Morfogênicas de Gramíneas Forrageiras Tropicais sob Diferentes Condições Hídricas do Solo ${ }^{1}$
}

\author{
Manoel Messias Pereira da Silva ${ }^{2}$, Hernan Maldonado Vasquez ${ }^{3}$, Ricardo Enrique Bressan- \\ Smith $^{4}$, José Fernando Coelho da Silva ${ }^{5}$, Eleonora D'Avila Erbesdobler ${ }^{6}$, Paulo Sérgio Cruz \\ de Andrade Junior ${ }^{7}$
}

RESUMO - Quatro gramíneas forrageiras (Setaria anceps Stapf., Hemarthria altissima [Poir] Stapf. \& Hubbard, Acroceras macrum Stapf. e Brachiaria purpurascens [Raddi] Henr.), foram estabelecidas por mudas, em vasos plásticos com diferentes condições hídricas, para se avaliar algumas características morfogênicas e estruturais. As irrigações foram controladas pela pesagem individual dos vasos e pela saturação relativa à porosidade total (SRPT) para cada nível hídrico do solo. Utilizou-se o delineamento de blocos casualizados, com três repetições, em que os tratamentos consistiram de quatro espécies, submetidas a quatro níveis hídricos: deficiência hídrica (50\% de SRTP) (D); controle (100\% de SRTP) (C); alagamento 1 (120\% de SRTP) (A1) e alagamento 2 (150\% de SRTP) (A2). Foram identificados três perfilhos basais vaso ${ }^{-1}$, para as mensurações da morfogênese e das características estruturais das plantas: taxa de aparecimento de folhas individuais (TAP), filocrono de folhas individuais (FIL), taxa de alongamento de folhas individuais (TAL), comprimento final da lâmina foliar (CF), número total de folhas expandidas (FT) e número total de folhas verdes (FV). A TAL e o FIL foram inversamente proporcionais para o capim-setária, que apresentou resposta linear para a umidade no solo, enquanto os demais capins tiveram respostas quadráticas. O capim-hemárthria apresentou as maiores TAP para maior umidade do solo. O CF, aos 45 dias de rebrota, seguiu a tendência da TAL, com maiores valores para o capim-setária, alcançando até 0,34 m. O capim-hemárthria apresentou os maiores valores de CF entre as gramíneas de menor porte, em todos os níveis hídricos solo. Tanto o FT quanto o FV tiveram efeito significativo das gramíneas na interação com o nível hídrico dos vasos. O capim-hemárthria mostrou os maiores números de FT e FV em todos os níveis hídricos, com até 12 folhas perfilho $^{-1}$. As diferenças estruturais observadas entre as espécies estudadas poderiam ser úteis para a escolha dos materiais de acordo com a disponibilidade de áreas sujeitas a inundações ao longo do ano.

Palavras-chave: Acroceras, alagamento, Brachiaria, Hemarthria, lâmina foliar, Setaria

\section{Morphogenic and Structural Responses of Tropical Forage Grasses to Different Soil Moisture Conditions}

\begin{abstract}
Some morphogenic and structural characteristics of four forage grasses grown under four soil moisture conditions were assessed. The forage species were: Setaria anceps Stapf., Hemarthria altissima [Poir] Stapf. \& Hubbard, Acroceras macrum Stapf. and Brachiaria purpurascens [Raddi] Henr. Soil moisture level was controlled by weighing individual pots and by relative saturation of total porosity (RSTP). A randomized block design with three replications was used. Four plants of each specie were submitted to four soil moisture levels: deficit (50\% RSTP)(D), control (100\% RSTP) (C), water logging 1 (120\% RSTP) (W1) and water logging 2 (150\% RSTP) (W2). Three tillers in each plastic pot were used for morphogenic and structural characteristics measurements of the plants: leaf appearance rate (LAR), phyllochron of individual leaves (PHYL), leaf elongation rate (LER), final length of individual leaves (FL), number of expanded leaves (EL) and number of individual green leaves (GL). LER and PHYL in Setariagrass varied linearly and inversely with soil moisture, while others grasses showed quadratic responses. Hemarthriagrass presented the highest LAR under water logged soil condition. FL on day 45 of regrowth followed the same pattern of LAR, with higher values in setariagrass, reaching up to 0.34 m. Hemarthriagrass presented the highest values of FL among the short grasses, in all of the soil moisture condition. Both EL and GL showed significant grasses and soil moisture levels interaction. Hemarthriagrass showed higher values of EL and GL under any moisture level, reaching 12 leaves per stem. The structural differences observed among the studied species may be useful criteria for the selection of grasses according to soil flooding condition throughout the year.
\end{abstract}

Key Words: Acroceras, Brachiaria, flooding, Hemarthria, leaf blade, Setaria

\footnotetext{
${ }^{1}$ Parte do trabalho de tese de doutorado do primeiro autor, financiado com recursos da Fundação de Amparo à Pesquisa do Estado do Rio de Janeiro (FAPERJ).

2 Zootecnista, M.S. e D.S. em Produção Animal, UENF. Endereço eletrônico: manoel02811@upis.com.br

${ }^{3}$ Professor Associado do LZNA/CCTA/UENF e bolsista de Produtividade em Pesquisa (CNPq). Endereço eletrônico: maldonado@uenf.br

${ }^{4}$ Professor Associado do Laboratório de Melhoramento Genético Vegetal (LMGV), CCTA/UENF. Endereço eletrônico: bressan@uenf.br

5 Professor Titular do LZNA/CCTA/UENF e bolsista de Produtividade em Pesquisa (CNPq). Endereço eletrônico: jcoelho@uenf.br

6 Zootecnista, M.S. e D.S. em Biociências e Biotecnologia, UENF.

${ }^{7}$ Médico Veterinário. Endereço eletrônico: psacjunior@censanet.com.br.
} 


\section{Introdução}

O principal obstáculo à produção animal nas regiões tropicais e subtropicais tem sido o suprimento irregular de forragem durante o ano, principalmente em razão do estresse hídrico sazonal ocasionado por secas e alagamentos do solo (Jones, 1979). Uma das limitações das forrageiras tropicais quando submetidas ao alagamento é a redução drástica da difusão do oxigênio na região radicular das plantas, provocando hipóxia ou anóxia, limitando a absorção de minerais e de água pelas raízes. Em condições de alagamento, em plantas não-tolerantes, a assimilação e a translocação de carbono são reduzidas, como conseqüência do fechamento dos estômatos. Essa redução da fotossíntese, inicialmente atribuída ao fechamento dos estômatos, também é conseqüência, entre outros fatores, da acumulação dos fotoassimilados e do desequilíbrio hormonal (Baruch, 1994b). Em plantas tolerantes ao alagamento, o fechamento dos estômatos geralmente não ocorre e o metabolismo da raiz não é tão alterado pela anoxia, em decorrência à eficiente difusão e do transporte do oxigênio nas raízes (Armstrong et al., 1991).

O cultivo de plantas forrageiras tolerantes ao alagamento é uma boa alternativa para regiões sujeitas a inundações periódicas e consideradas pouco produtivas para a pecuária. Porém, existem poucos estudos sobre essas forrageiras, tornando-se necessário conhecer melhor os mais diversos aspectos de seu comportamento, como sua habilidade em tolerar solos alagados (Flaresso \& Saibro, 1991).

Todas as gramíneas são capazes de ajustar seu crescimento e desenvolvimento em resposta ao alagamento e, até certo limite, podem compensar a alteração na disponibilidade do oxigênio. Entretanto, algumas gramíneas de origem africana apresentam estruturas capazes de responder às variações no ambiente do solo alagado, com caules e raízes diferenciadas (Botrel, 1983; Mitidieri, 1988; Baruch, 1994a). Entre elas, encontram-se as espécies nativas da África Brachiaria purpurascens (Raddi) Henr., a Hemarthria altissima [Poir] Stapf \& C. E. Hubb, a Acroceras macrum Stapf. e Setaria anceps Stapf., que apresentam boa adaptação em regiões de várzea e de baixa umidade, sendo também tolerantes ao alagamento temporário do solo.

Informações básicas sobre os aspectos morfológicos da forrageira são imprescindíveis para maior precisão do nicho ecológico ideal para sua utilização (Deschamps, 1997). Segundo Wilhelm \& McMaster (1995), crescimento é o aumento irreversível na dimensão física de um indivíduo ou órgão, em determinado intervalo de tempo, enquanto o desenvolvimento inclui o processo de iniciação de órgãos (morfogênese) até a diferenciação, podendo incluir o processo de senescência. A morfogênese pode ser definida como a dinâmica de geração e expansão da forma da planta no espaço, podendo ser expressa em termos de taxa de aparecimento (organogênese) e expansão de novos órgãos e de sua senescência (Lemaire,1997).

As características morfogênicas podem ser influenciadas pelos fatores do meio ambiente, mas são determinadas geneticamente (Chapman \& Lemaire, 1993). O intervalo de tempo para o aparecimento de duas folhas sucessivas, expresso em dias ou diasgrau, é geneticamente determinado e condicionado pelos fatores do meio (Pinto et al., 1994). O inverso do intervalo de tempo para o crescimento de duas folhas sucessivas estima a taxa de aparecimento de folhas, expresso em folhas por dia, também é função dos genótipos e do meio ambiente. As taxas de aparecimento e alongamento foliares e a duração das folhas constituem os fatores morfogênicos do perfilho que, sob ação do ambiente, determinam as características estruturais do relvado, como o número e o tamanho de folhas e a densidade de perfilhos, responsáveis pelo índice de área foliar do relvado (Chapmam \& Lemaire, 1993). O alongamento da lâmina foliar cessa com a exposição da lígula (Langer, 1972) quando a folha torna-se adulta, completamente expandida. Posteriormente, instala-se o processo de senescência foliar, cuja intensidade varia com as estações do ano e os fatores de ambiente. O número de folhas verdes por perfilho é razoavelmente constante, conforme o genótipo, as condições de meio e o manejo.

Em virtude da escassez de informações sobre a resposta de gramíneas forrageiras tropicais submetidas ao alagamento, aquelas consideradas tolerantes ao encharcamento devem ser estudadas para o melhor entendimento da dinâmica de seu desenvolvimento. $\mathrm{O}$ conhecimento das taxas de aparecimento, alongamento e senescência foliares e de perfilhamento se reveste de fundamental importância para orientar o manejo das forrageiras, com objetivo de maximizar a eficiência de colheita sob sistema de corte ou pastejo rotacionado, prevenindo perdas de folhas por 
senescência e morte (Gomide, 1997). Assim, a identificação de variações nas respostas morfogênicas de gramíneas tropicais é de fundamental importância para sua seleção e melhoramento genético à condição de inundação do solo.

Em áreas com solos permanentemente encharcados ao longo do ano, como a planície costeira da região Norte Fluminense, seria recomendável o uso de gramíneas tropicais tolerantes ao alagamento. Este trabalho foi realizado com o objetivo de avaliar os efeitos de diferentes condições hídricas do solo sobre as características morfogênicas e estruturais de quatro gramíneas tropicais: capim-setária (Setaria anceps Stapf.), capim-hemárthria (Hemarthria altissima [Poir] Stapf. \& Hubbard), capim-do-nilo (Acroceras macrum Stapf.) e capim-angola (Brachiaria purpurascens [Raddi] Henr.).

\section{Material e Métodos}

O ensaio foi conduzido em casa de vegetação, com cobertura de lona plástica transparente, na Unidade de Apoio à Pesquisa (UAP) do Centro de Ciências e Tecnologias Agropecuárias (CCTA) da Universidade Estadual do Norte Fluminense (UENF), em Campos dos Goytacazes, RJ.

Foram avaliadas quatro gramíneas consideradas de boa tolerância ao encharcamento do solo: capimsetária (Setaria anceps Stapf.), capim-angola (Brachiaria purpurascens [Raddi] Henr.), capimhemárthria (Hemarthria altissima [Poir.] Stapf \& Hubbard) e capim-do-nilo (Acroceras macrum Stapf.). Mudas enraizadas das quatro forrageiras, coletadas no Setor de Forragicultura do LZNA, nas dependências do Colégio Agrícola Estadual “Antônio Sarlo” no município de Campos dos Goytacazes, RJ foram plantadas em vasos plásticos, com furos, com capacidade para $6.10^{-3} \mathrm{~mm}^{3}$ de solo, apoiados em pratos plásticos. O solo para enchimento dos vasos, classificado como
Latossolo Amarelo Distrófico, procedente do Setor de Forragicultura do LZNA, foi passado em peneiras com malhas de $4 \mathrm{~mm}$ e amostrado, para análise química no Laboratório de Análises Químicas de Solo da Universidade Federal Rural do Rio de Janeiro, Campus Dr. Leonel Miranda, em Campos dos Goytacazes, RJ. O resultado da análise (Tabela 1) indicou a necessidade de correção da acidez por meio da elevação da saturação de bases em 50\% (Werner et al., 1986).

No dia 23 de julho de 2002, após o preparo do solo, efetuou-se o enchimento dos vasos e o plantio das mudas das gramíneas, realizando-se a pesagem individual das mudas e dos respectivos vasos preenchidos com solo, com o objetivo de controlar o peso de cada vaso, para posterior aplicação dos tratamentos. A adubação básica do solo para cada vaso foi feita com $110 \mathrm{mg} / \mathrm{dm}^{3}$ de N (sulfato de amônio), $150 \mathrm{mg} / \mathrm{dm}^{3} \mathrm{de}$ $\mathrm{P}$ (superfosfato simples), $50 \mathrm{mg} / \mathrm{dm}^{3}$ de $\mathrm{K}$ (cloreto de potássio). Após o plantio e durante o estabelecimento das mudas nos vasos, foram realizadas irrigações, com água de torneira, controlando-se a quantidade de água aplicada em cada vaso por meio da pesagem individual, de modo a manter a umidade do solo com $80 \%$ de saturação relativa à sua porosidade total (SRPT) (Kiehl, 1979).

Em 21 de agosto de 2002, após o estabelecimento das plantas, foi realizado o corte de uniformização das quatro gramíneas, a $5 \mathrm{~cm}$ de altura do solo, utilizandose uma "tesoura-podão". Em seguida, os tratamentos foram sorteados de acordo com o arranjo experimental determinado para o ensaio. Foi utilizado o delineamento experimental em blocos ao acaso, com três repetições, em que os tratamentos foram constituídos pelas quatro gramíneas, submetidas a quatro regimes hídricos do solo (controle [C], 100\% de SRPT; deficiência hídrica [D], 50\% de SRPT; alagamento 1 [A1], 120\% de SRPT; alagamento 2 [A2], 150\% de SRPT), perfazendo um total de 48 vasos, ou unidades experimentais, dispostos sobre bancadas de madeira. A

Tabela 1 - Resultados da análise química do solo

Table 1 - Results of soil chemical analysis

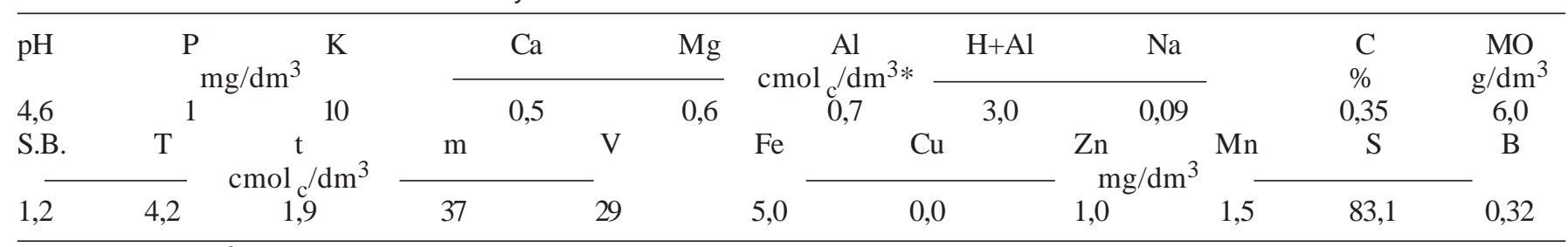

Centimo carga/ $/ \mathrm{dm}^{3}$ de solo (Centimol charge/dm ${ }^{3}$ of soil). 
quantidade de água (Qw) adicionada/tratamento foi determinada pela fórmula $\mathrm{Qw}=$ Volume do Solo $\mathrm{x}$ Porosidade total (PT). A porosidade total (PT) do solo foi calculada a partir das densidades do solo (ds) e da partícula (dp), considerando-se a massa e o volume de solo, de acordo com a seguinte fórmula: PT = 1 - (ds/ dp), conforme a metodologia descrita por Kiehl (1979). Durante o período experimental, a água perdida por evapotranspiração foi reposta diariamente pelo método gravimétrico, com o uso de balança, a partir do conhecimento prévio dos pesos de cada vaso no estabelecimento dos tratamentos. Os vasos plásticos que receberam os tratamentos de lâmina d'água (A1 e A2) tiveram seus furos devidamente vedados. Em 28 de agosto de 2002, uma semana após o corte de uniformização, por ocasião do aparecimento de novos perfilhos a partir de gemas basais (abaixo da altura de corte), três perfilhos basilares foram aleatoriamente identificados em cada vaso, com o uso de anéis de nylon coloridos, destinados às mensurações morfogênicas e estruturais das plantas. Com o uso de régua milimitrada, foram efetuadas medições, a cada dois dias, do comprimento das lâminas foliares dos perfilhos marcados, anotando-se os valores em planilhas. O comprimento de cada lâmina emergente foi medido do seu ápice até a lígula da última folha expandida. O comprimento da lâmina foliar foi medido até sua completa expansão, ou seja, até o aparecimento da lígula. As medições nos perfilhos marcados ocorreram durante 45 dias, entre os dias 28 de agosto e 06 de outubro de 2002.

A partir dos dados referentes ao crescimento de folhas, foram estimadas as seguintes variáveis:

Taxa de aparecimento de folhas individuais (TAP, folhas dia $^{-1}$ perfilho ${ }^{-1}$ ) = divisão do número de folhas surgidas por perfilho, no período, pelo número de dias envolvidos.

Filocrono de folhas individuais (FIL, dias folha $\left.{ }^{-1}\right)=$ inverso da TAP; obtido pelo intervalo de tempo, em dias, entre a completa expansão de duas folhas sucessivas.

Taxa de alongamento de folhas individuais (TAL, mm dia ${ }^{-1}$ ) = subtração do comprimento inicial do comprimento final de cada lâmina, dividindo-se a diferença pelo número de dias envolvidos.

Comprimento final da lâmina foliar $(\mathrm{CL}, \mathrm{m})=$ distância entre o ápice e a lígula da folha expandida.

Número de folhas totais expandidas (FT, folhas perfilho $^{-1}$ ) $=$ contagem do número de folhas expandi- das (tanto verdes como senescentes) por perfilho, durante o período de avaliação.

Número de folhas verdes $\left(\mathrm{FV}\right.$, folhas perfilho $\left.{ }^{-1}\right)=$ contagem do número total de folhas, que, ao final do período de avaliação, não apresentavam qualquer sinal de senescência.

As análises estatísticas foram feitas empregandose os procedimentos do programa SAEG (Sistema para Análises Estatísticas e Genéticas), desenvolvido pela Universidade Federal de Viçosa, MG (UFVSAEG, 1997). Para o fator quantitativo níveis hídricos do solo, seus efeitos foram avaliados por meio de análise de regressão. Na comparação das médias para o fator qualitativo, utilizou-se o teste Tukey, a 5\% de probabilidade.

O modelo estatístico adotado para as análises foi o seguinte:

$$
\mathrm{Y}_{\mathrm{ikj}}=\mu+\beta \mathrm{i}+\alpha \mathrm{j}+\delta_{\mathrm{k}}+(\alpha \delta)_{\mathrm{jk}+} \varepsilon_{\mathrm{ijk}}
$$

em que: $\mathrm{Y}_{\mathrm{ikj}}=$ variável relativa do bloco i, na gramínea j e na condição hídrica $\mathrm{k} ; \mu$ = média geral; $\beta \mathrm{i}=$ efeito do bloco, $\mathrm{i}=(1,2,3)$; $\alpha \mathrm{j}$ = efeito da gramínea, $\mathrm{j}=(1$, 2, 3, 4); $\delta_{\mathrm{k}}=$ efeito da condição hídrica, $\mathrm{k}=(1,2,3,4)$; $(\alpha \delta)_{\mathrm{jk}}=$ efeito da interação entre gramínea j e condição hídrica $\mathrm{k} ; \varepsilon_{\mathrm{ijk}}=$ erro aleatório, normal e independente, distribuído com média 0 e variância $\sigma^{2}$, na gramínea $j$ e na condição hídrica $k$.

\section{Resultados e Discussão}

A análise de variância revelou que as quatro gramíneas estudadas apresentaram diferenças significativas $(\mathrm{P}<0,01)$ quanto aos parâmetros morfogênicos avaliados, em resposta ao efeito do nível de saturação de água do solo. Na Tabela 2 são apresentados os valores médios dos parâmetros de morfogênese avaliados para as quatro gramíneas.

A taxa de aparecimento de folhas (TAP) foi influenciada pela disponibilidade de água no solo, evidenciada pelos efeitos significativos da interação gramínea $\mathrm{x}$ nível hídrico do solo $(\mathrm{P}<0,01)$ sobre o aparecimento de folhas nas diferentes espécies. $\mathrm{O}$ capim-setária apresentou relação crescente de aparecimento de folhas com a água disponível no solo, com regressão linear significativa a $1 \%$ de probabilidade, enquanto, para os demais capins, os níveis hídricos influenciaram de forma quadrática a taxa de aparecimento das folhas (Figura 1). 

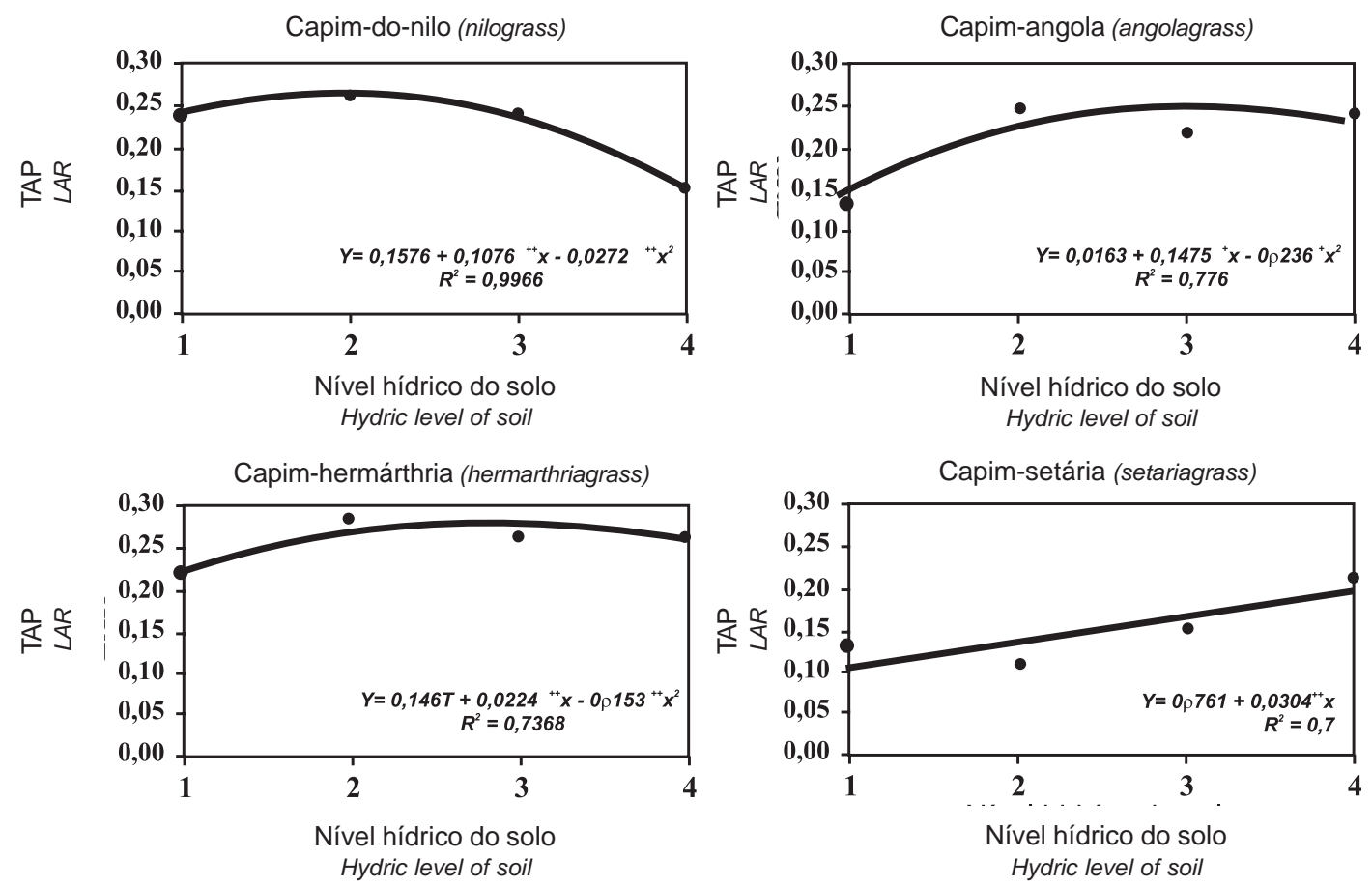

Figura 1 - Taxa de aparecimento de folhas individuais (TAP, folhas dia-1 perfilho ${ }^{-1}$ ) de quatro gramíneas tropicais, em função do nível hídrico do solo (HIDR) ${ }^{1}$.

Figure 1 - Leaf appearance rate of individual leaves (LAR, leaves day ${ }^{-1}$ tiller $\left.^{-1}\right)$ of four tropical grasses, according to hydric level of soil (HYDR).

1 Nível de saturação relativa da porosidade total do solo: HIDR 1 = 50\%; HIDR 2 = 100\%; HIDR 3 = 125\%; HIDR $4=150 \%$.

* Significativo a $5 \%$ pelo teste t.

** Significativo a $1 \%$ pelo teste $t$.

1 Level of relative saturation of total soil porosity: HYDR $1=50 \% ;$ HYDR $2=100 \% ;$ HYDR $3=125 \% ;$ HYDR $4=150 \%$.

* Significant at $5 \%$ of probability by Tukey test.

** Significant at $1 \%$ of probability by Tukey test.

As maiores taxas de aparecimento de folhas foram apresentadas pelo capim-hemárthria, a partir da completa saturação com água dos poros do solo, comprovando o vigor da espécie para desenvolvimento em áreas mal-drenadas, enquanto o capim-do-nilo foi superior quando o solo apresentou apenas metade de seus poros saturados pela água (Tabela 2). Alguns autores acreditam que espécies com maior velocidade de emissão de folhas, quando submetidas ao pastejo, são mais adaptadas a desfolhações mais freqüentes (Lemaire \& Chapman, 1996), sugerindo que, em condições de encharcamento do solo, o capimhemárthria renova suas folhas mais rapidamente que os demais capins, possivelmente em razão do melhor aproveitamento dos recursos disponíveis (água, luz e nutrientes). As taxas de aparecimento de folhas apresentadas na Tabela 2, de modo geral, foram próximas dos valores encontrados em estudos com outras gramíneas tropicais e superiores aos dados obtidos com gramíneas temperadas. Pinto et al. (1994) encontraram TAP de 0,233 folhas dia ${ }^{-1}$ perfilho $^{-1}$ em cultivares de capim-guiné (Panicum maximum) cultivados em vasos plásticos e adubados com diferentes doses de nitrogênio. Para um joio, uma gramínea temperada do gênero Lolium, mesmo com doses elevadas de adubo nitrogenado, a TAP não passou de 0,134 folhas dia $^{-1}$ perfilho ${ }^{-1}$ (Thomas, 1983).

O filocrono, calculado como o inverso da TAP, também foi afetado pela disponibilidade de água no solo, apresentando efeitos significativos da interação gramínea x nível hídrico do solo $(\mathrm{P}<0,01)$, com respostas quadráticas para os níveis hídricos estudados. O comportamento do filocrono de folhas individuais em resposta aos diferentes níveis hídricos do solo é apresentado na Figura 2. Quanto aos valores médios de filocrono para os capins dentro de cada nível hídrico, o capim-setária apresentou o maior valor médio de filocrono com o menor nível hídrico do solo, 
Tabela 2 - Taxa de aparecimento de folhas individuais (TAP), filocrono de folhas individuais (FIL), taxa de alongamento de folhas individuais (TAL), comprimento final da lâmina foliar (CF), número de folhas totais por perfilho (FT), número de folhas verdes por perfilho (FV), de quatro gramíneas tropicais, em função do nível hídrico do solo ${ }^{1}$

Table 2 - Leaf appearance rate of individual leaves (LAR), phyllocron of individual leaves ( $P H Y L$ ), leaf elongation rate of individual leaves (LER), final length of individual leaves ( $F L)$, number of individual leaves expanded per tiller (LE), number of individual green leaves per tiller (LL) of four tropical grasses, as influenced by soil hydric level (HYDR)

\begin{tabular}{|c|c|c|c|c|}
\hline $\begin{array}{l}\text { Nível hídrico } \\
\text { Hydric level (HYDR) }\end{array}$ & $\begin{array}{l}\text { Capim-do-nilo } \\
\text { Nilograss }\end{array}$ & $\begin{array}{l}\text { Capim-angola } \\
\text { Angolagrass }\end{array}$ & $\begin{array}{c}\text { Capim-hemárthria } \\
\text { Hemarthriagrass }\end{array}$ & $\begin{array}{c}\text { Capim-setária } \\
\text { Setariagrass }\end{array}$ \\
\hline \multicolumn{5}{|c|}{ TAP (folhas/dia.perfilho) } \\
\hline \multicolumn{5}{|c|}{ LAR(leaves/day.tiller) } \\
\hline 1 & $0,24 \mathrm{a}$ & $0,13 c$ & $0,22 \mathrm{~b}$ & $0,13 c$ \\
\hline 2 & $0,26 \mathrm{~b}$ & $0,25 c$ & $0,28 \mathrm{a}$ & $0,11 \mathrm{~d}$ \\
\hline 3 & $0,24 b$ & $0,22 \mathrm{c}$ & $0,26 \mathrm{a}$ & $0,15 \mathrm{~d}$ \\
\hline 4 & $0,15 \mathrm{~d}$ & $0,24 b$ & 0,26 a & $0,22 \mathrm{c}$ \\
\hline \multicolumn{5}{|c|}{ FIL (dias/folha.perfilho) } \\
\hline \multicolumn{5}{|c|}{ PHYL (days/leaf.tiller) } \\
\hline 1 & $4,18 \mathrm{a}$ & $7,67 \mathrm{a}$ & $4,60 \mathrm{~b}$ & 7,67 a \\
\hline 2 & $3,83 c$ & $4,07 \mathrm{~b}$ & $3,54 d$ & 9,20 a \\
\hline 3 & $4,18 \mathrm{c}$ & $4,60 \mathrm{~b}$ & $3,83 \mathrm{~d}$ & 6,57 a \\
\hline 4 & $6,57 \mathrm{a}$ & $4,18 \mathrm{c}$ & $3,83 \mathrm{~d}$ & $4,60 \mathrm{~b}$ \\
\hline \multicolumn{5}{|c|}{ TAL (mm/dia.perfilho) } \\
\hline \multicolumn{5}{|c|}{$\operatorname{LER}(\mathrm{mm} /$ day.tiller) } \\
\hline 1 & $15,3 \mathrm{a}$ & 13,5 a & $14,9 \mathrm{a}$ & $9,2 \mathrm{~b}$ \\
\hline 2 & $12,1 \mathrm{c}$ & 24,8 a & $20,4 \mathrm{~b}$ & $13,8 \mathrm{c}$ \\
\hline 3 & $18,8 \mathrm{a}$ & $13,0 \mathrm{~b}$ & $12,2 \mathrm{~b}$ & $18,8 \mathrm{a}$ \\
\hline 4 & $11,5 \mathrm{c}$ & $15,2 \mathrm{~b}$ & $13,3 \mathrm{c}$ & 18,6 a \\
\hline \multicolumn{5}{|l|}{ CF (m/folha) } \\
\hline \multicolumn{5}{|l|}{$F L(\mathrm{~m} / \mathrm{leaf})$} \\
\hline 1 & 0,1419b & $0,1194 \mathrm{c}$ & 0,1630 a & $0,0956 \mathrm{~d}$ \\
\hline 2 & $0,1348 c$ & $0,1257 \mathrm{c}$ & $0,1791 \mathrm{a}$ & $0,1508 \mathrm{~b}$ \\
\hline 3 & 0,1623b & $0,1143 c$ & 0,1568b & 0,3173a \\
\hline 4 & $0,1458 c$ & $0,1062 d$ & $0,1728 b$ & $0,3425 a$ \\
\hline \multicolumn{5}{|c|}{ FT (n ${ }^{0}$ de folhas totais/perfilho) } \\
\hline \multicolumn{5}{|c|}{ EL (n $n^{\circ}$ total leaves/tiller) } \\
\hline 1 & $11 \mathrm{a}$ & $6 \mathrm{c}$ & $10 \mathrm{~b}$ & $6 \mathrm{c}$ \\
\hline 2 & $12 \mathrm{~b}$ & $11 \mathrm{c}$ & 13 a & $5 \mathrm{~d}$ \\
\hline 3 & $11 \mathrm{a}$ & $10 \mathrm{~b}$ & $12 \mathrm{a}$ & $7 \mathrm{c}$ \\
\hline 4 & $7 \mathrm{~d}$ & $11 b$ & $12 \mathrm{a}$ & $10 \mathrm{c}$ \\
\hline \multicolumn{5}{|c|}{ FV (n ${ }^{\circ}$ defolhas verdes/perfilho) } \\
\hline \multicolumn{5}{|c|}{ GL ( $n^{\circ}$ total green leaves/tiller) } \\
\hline 1 & 9 a & $4 \mathrm{~b}$ & $8 \mathrm{a}$ & $4 \mathrm{~b}$ \\
\hline 2 & $10 \mathrm{ab}$ & $8 \mathrm{~b}$ & $11 \mathrm{a}$ & $4 \mathrm{c}$ \\
\hline 3 & $11 \mathrm{a}$ & $8 \mathrm{~b}$ & $11 \mathrm{a}$ & $6 \mathrm{~b}$ \\
\hline 4 & $6 \mathrm{~b}$ & 9 a & $10 \mathrm{a}$ & $8 \mathrm{ab}$ \\
\hline
\end{tabular}

${ }^{1}$ Nível de saturação relativa da porosidade total do solo. HIDR $1=50 \%$; HIDR $2=100 \%$; HIDR $3=25 \%$; HIDR $4=150 \%$. Médias seguidas das mesmas letras, na linha, não diferem $(P \leq 0,05)$ entre si, segundo o teste Tukey.

${ }^{1}$ Level of relative saturation of total porosity of soil. HYDR $1+50 \% ;$ HYDR $2=100 \% ;$ HYDR 3=125\%; HYDR $4=150 \%$.

Means followed by the same letter, within arow, do not differ ( $P \leq .05)$, by Tukey test.

o que sugere que esta gramínea apresenta o maior intervalo de tempo (em dias) para a completa formação de uma folha ou, ainda, menor relação de folhas dia $^{-1}$ perfilho $^{-1}$ (TAP). Para o capim-mombaça (Panicum maximum Jacq.) adubado com doses crescentes de nitrogênio, Garcez Neto et al. (2002) encontraram valores de 8 a 12 dias para expansão completa da folha, do ápice até o aparecimento da lígula das lâminas foliares. Esses resultados foram muito próxi- mos dos encontrados para o capim-setária (Tabela 2), que, assim como o capim-mombaça, é uma planta de crescimento cespitoso, com presença de bainhas foliares bastante desenvolvidas, as quais têm relação direta com o maior ou menor tempo destinado ao desenvolvimento da lâmina foliar (Nabinger, 1996). Para as demais gramíneas avaliadas neste estudo, os valores médios para completo aparecimento de uma folha foram próximos aos de filocrono relatados por 

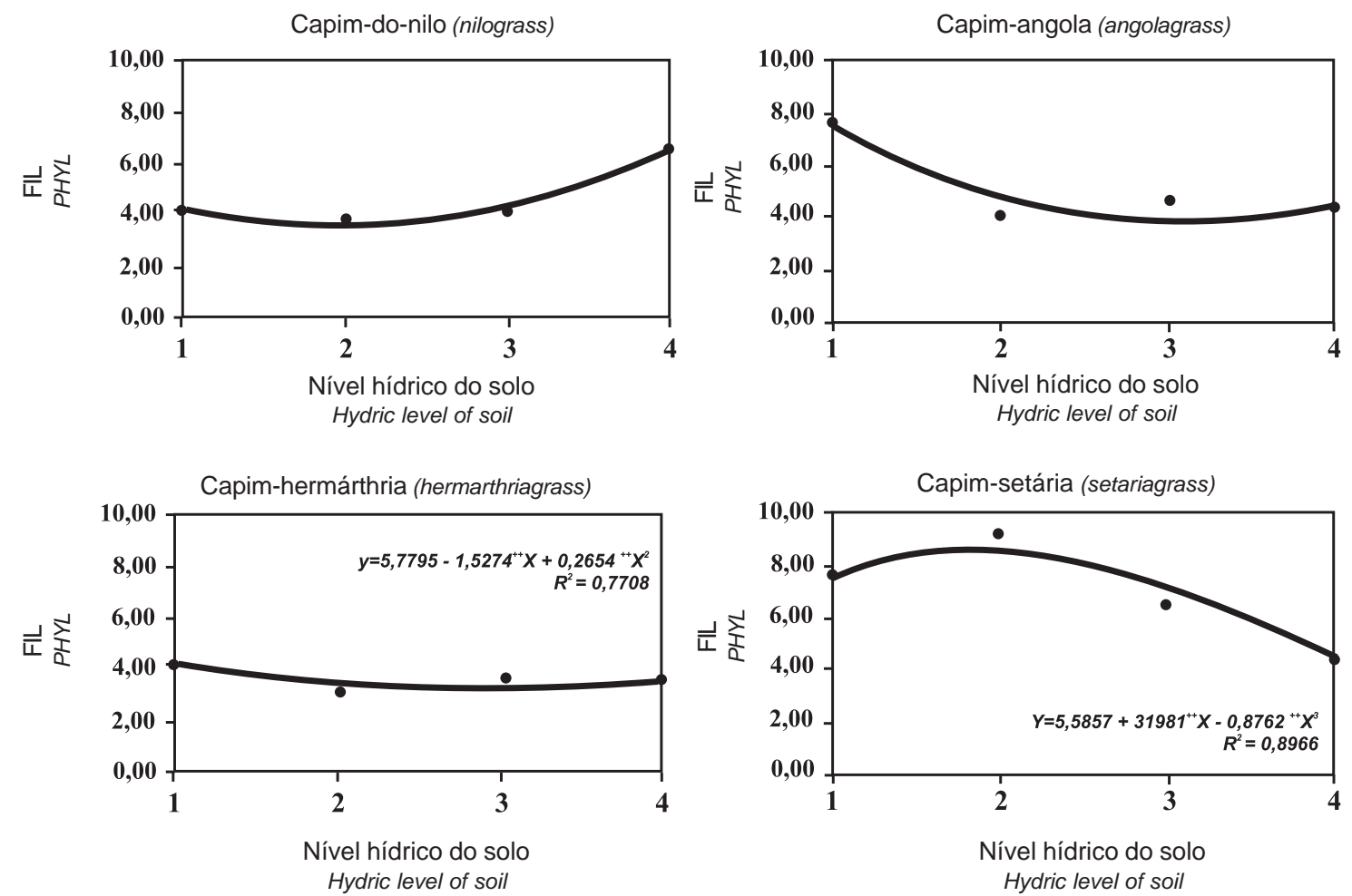

Figura 2 - Filocrono de folhas individuais (FIL, dias folha ${ }^{-1}$ perfilho) de quatro gramíneas tropicais, em função do nível hídrico do solo (HIDR) ${ }^{1}$.

Figura 2 - Phyllochron of individual leaves (PHYL, days leaft ${ }^{-1}$ tiller) of four tropical grasses, according to hydric level of soil (HYDR)1.

1 Nível de saturação relativa da porosidade total do solo: HIDR 1 = 50\%; HIDR 2 = 100\%; HIDR 3 = 125\%; HIDR 4 = 150\%.

** Significativo a $1 \%$ pelo teste t.

1 Level of relative saturation of total soil porosity: HYDR $1=50 \% ; H Y D R 2=100 \% ; H Y D R 3=125 \% ; H Y D R 4=150 \%$.

** Significant at $1 \%$ of probability by Tukey test.

Corsi et al. (1994) para espécies de Brachiaria, que foram de 5,27, 5,51 e 3,97 dias folha ${ }^{-1}$, respectivamente para $B$. brizantha, $B$. decumbens e $B$. humidicola. Em alguns estudos sobre a TAP, após corte ou pastejo, foram observados que, quanto maior o tamanho da bainha, menor a TAP, uma vez que a folha leva mais tempo para percorrer um trajeto maior entre seu ponto de conexão com o meristema e a extremidade do pseudo-colmo das bainhas das folhas mais velhas. Desse modo, para bainhas maiores, haveria maior trajeto a ser percorrido pela folha no interior do pseudo-colmo e a TAP seria, então, reduzida (Garcez Neto et al., 2002). Outro fato importante relativo à redução da taxa de aparecimento de folhas do perfilho é sua dependência do avanço da idade da planta, uma vez que a distância a ser percorrida pela folha em expansão eleva sucessivamente com o aparecimento de cada folha (Miglietta, 1991). Portanto, não seria correto afirmar que o capim-setária, em comparação às demais gramíneas avaliadas, é mais sensível ao déficit hídrico, por apresentar valores de filocrono superiores aos das gramíneas estoloníferas. Essa diferença pode ser atribuída principalmente à característica estrutural da espécie, que apresenta porte ereto e folhas mais longas que as demais forrageiras desse estudo.

A taxa de alongamento foliar (TAL) variou $(\mathrm{P}<0,01)$ conforme a interação das gramíneas e os níveis hídricos do solo (Figura 3). Entretanto, a equação de regressão para TAL em relação ao nível hídrico somente foi significativa $(\mathrm{P}<0,01)$ para o capim-setária, com aumento quadrático da taxa de alongamento foliar com a elevação da lâmina d'água nos vasos. Os valores médios da TAL em cada nível hídrico do solo foram efetivamente maiores $(\mathrm{P}<0,05)$ para o capim-setária (18,8 e 18,6 mm dia ${ }^{-1}$ nos níveis 3 e 4, respectivamente) quando os níveis de água do solo ficaram acima da saturação completa do mesmo, entretanto, o capim-do-nilo também alcançou TAL semelhante quando mantido sob o nível ligeiramente 
superior à saturação completa do solo, diminuindo no nível seguinte $\left(11,5 \mathrm{~mm} \mathrm{dia}^{-1}\right)$. A TAL demonstra que haveria uma relação direta com a produção forrageira (Gomide, 1997), o que poderia indicar que o capim-donilo responde de forma positiva ao alagamento do solo até atingir determinado limite de tolerância. Em condições de déficit hídrico moderado do solo, o capimsetária apresentou a menor taxa de alongamento foliar (9,2 $\left.\mathrm{mm} \mathrm{dia}^{-1}\right)$, demonstrando a sensibilidade desta espécie à deficiência hídrica. Alguns fatores externos, como o nutricional e hídrico do solo, devem ser considerados sobre a taxa de alongamento de folhas. Volenec \& Nelson (1983) atribuíram o aumento de $140 \%$ no alongamento foliar de uma gramínea temperada, a Festuca arundinacea, ao acréscimo dos níveis de adubo nitrogenado ao solo. Apesar do ritmo de crescimento de gramíneas tropicais e temperadas ser um pouco diferente, para esses dois grupos, o alongamento foliar poderia ser atribuído muito mais ao aumento expressivo do número de células que ao aumento no comprimento da célula ou de sua taxa de alongamento celular. Entretanto, o alongamento foliar também parece ser direcionado pelo movimento da água na planta, chamado “fluxo de massa”, promovendo pressão na parede celular e contribuindo para o alongamento celular dos tecidos vegetais. Portanto, para plantas de porte mais elevado, com sistema radicular mais desenvolvido, o aumento do fluxo de massa promovido pela maior disponibilidade de água no solo parece contribuir bastante para o alongamento de tecidos e de órgãos vegetais de gramíneas tropicais.

$\mathrm{Na}$ avaliação do comprimento final da folha (CF) aos 45 dias de rebrota, a interação entre o tamanho médio das folhas e o nível hídrico do solo foi significativa $(\mathrm{P}<0,01)$ apenas para o capim-setária (Figura 4). O aumento do CF em relação ao nível de saturação hídrica do solo seguiu a mesma tendência da taxa de alongamento foliar, com maiores valores médios para o capim-setária, de 0,32 e 0,34 m, respectivamente. Os resultados demonstraram ainda que o capimhemárthria foi superior $(\mathrm{P}<0,05)$ desde o menor nível de água no solo, sendo inferior apenas ao capim-
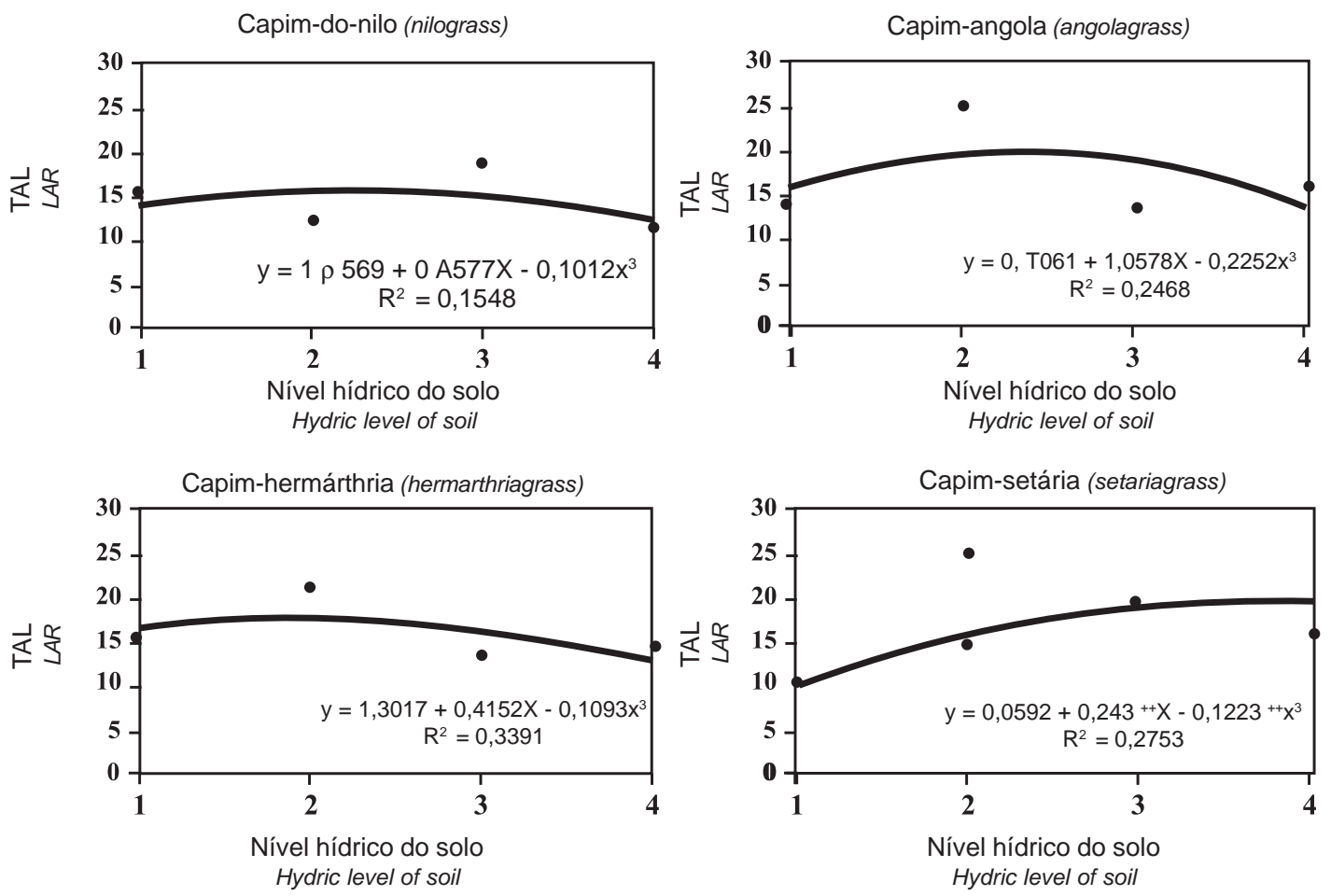

Figura 3 - Taxa de alongamento de folhas individuais (TAL, cm dia-1 perfilho-1) de quatro gramíneas tropicais em função do nível hídrico do solo (HIDR) ${ }^{1}$.

Figura 3 - Leaf alongation rate of individual leaves (LER, cm day-1 tiller $^{-1}$ ) of four tropical grasses, according to hydric level of soil (HYDR).

\footnotetext{
1 Nível de saturação relativa da porosidade total do solo: HIDR 1 = 50\%; HIDR 2 = 100\%; HIDR 3 = 125\%; HIDR 4 = 150\%.

** Significativo a $1 \%$ pelo teste $\mathrm{t}$.

1 Level of relative saturation of total soil porosity: HYDR $1=50 \% ;$ HYDR $2=100 \% ;$ HYDR $3=125 \% ;$ HYDR $4=150 \%$.

** Significant at $1 \%$ of probability by Tukey test.
} 

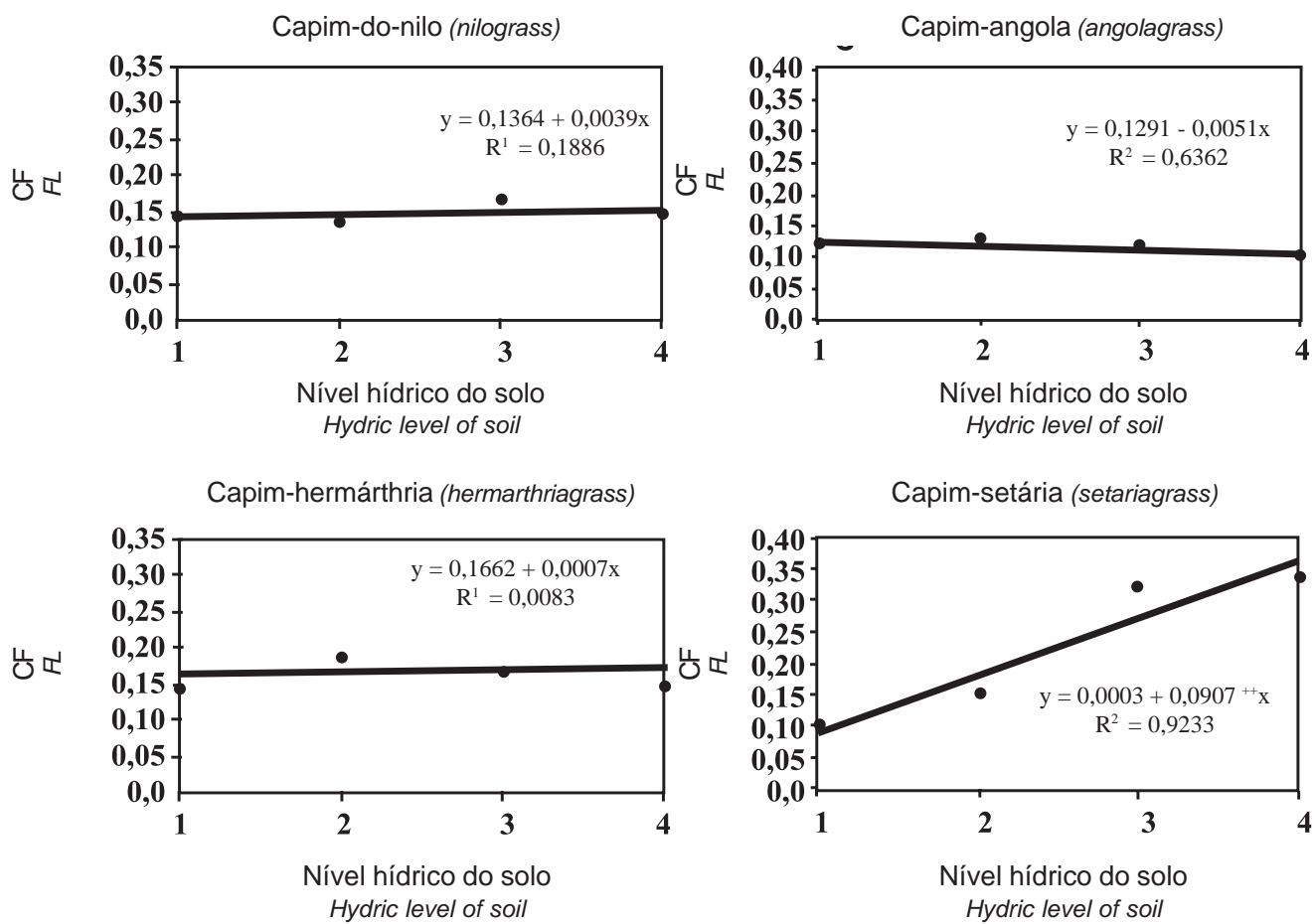

Figura 4 - Comprimento final de folhas individuais (CF, m) de quatro gramíneas tropicais, em função do nível hídrico do solo $\left(\right.$ HIDR) ${ }^{1}$.

Figura 4 - Final length of individual leaves (FL, $m$ ) of four tropical grasses, according to hydric level of soil (HYDR).

1 Nível de saturação relativa da porosidade total do solo: HIDR 1 = 50\%; HIDR 2 = 100\%; HIDR 3 = 125\%; HIDR 4 = 150\%.

** Significativo a $1 \%$ pelo teste $\mathrm{t}$.

1 Level of relative saturation of total soil porosity: HYDR $1=50 \% ;$ HYDR $2=100 \% ;$ HYDR $3=125 \% ;$ HYDR $4=150 \%$.

** Significant at $1 \%$ of probability by Tukey test.

setária, a partir dos níveis 3 e 4 . A diferença nos tamanhos das lâminas entre essas duas espécies deve ser considerada, uma vez que a folha de Setaria anceps, quando totalmente expandida, apresentará necessariamente maior tamanho que as das demais gramíneas do referido estudo. Existem ainda diferenças marcantes quanto ao porte destas gramíneas, pois o capim-hemárthria é uma gramínea estolonífera de crescimento rasteiro, enquanto o capim-setária é de porte elevado, crescimento cespitoso, com folhas naturalmente longas (Figura 5). Skinner \& Nelson (1995) descreveram que o comprimento final da lâmina foliar (e bainha) aumenta em sucessivas folhas de um perfilho até manter constante e que esse padrão é revertido quando os entrenós se alongam, de modo que a folha fica menor em relação à bainha e, portanto, a folha bandeira é mais curta que as folhas basais do perfilho. Diferenças no comprimento final das folhas também podem ser atribuídas aos valores de TAP, pois, quanto maiores esses valores, maior será a tendência de produção de folhas curtas por perfilho (Barbosa et al., 2002).
As quantidades de folhas totais expandidas (FT) e de folhas vivas (FV) foram influenciadas pela disponibilidade de água no solo, com respostas para todos os capins, exceto para o capim-setária, que apresentou resposta linear (Figuras 6 e 7). Tanto para o número de folhas totais quanto para o número de folhas vivas do capim-setária, houve aumento linear desses valores com a elevação do nível de água disponível nos vasos. Para os capins do nilo, hemárthria e angola, o efeito do nível hídrico sobre esses parâmetros foi quadrático, com os pontos críticos de máxima para o capim-do-nilo sob saturação hídrica do solo, calculados segundo as equações de FT e FV, de 1,98 e 2,06, respectivamente. Quanto aos valores médios para esses dois parâmetros (Tabela 2), houve destaque para o capim-hemárthria, que foi superior aos demais. Ao final do período de avaliação, o número de folhas vivas totais presentes por perfilho, para todos os níveis hídricos do solo, foi superior $(\mathrm{P}<0,05)$ para o capim-hemárthria. Entretanto, para o número total de folhas expandidas perfilho ${ }^{-1}$, o capimhemárthria não foi superior apenas no menor nível de água do solo. Neste caso, o capim-do-nilo apresentou 


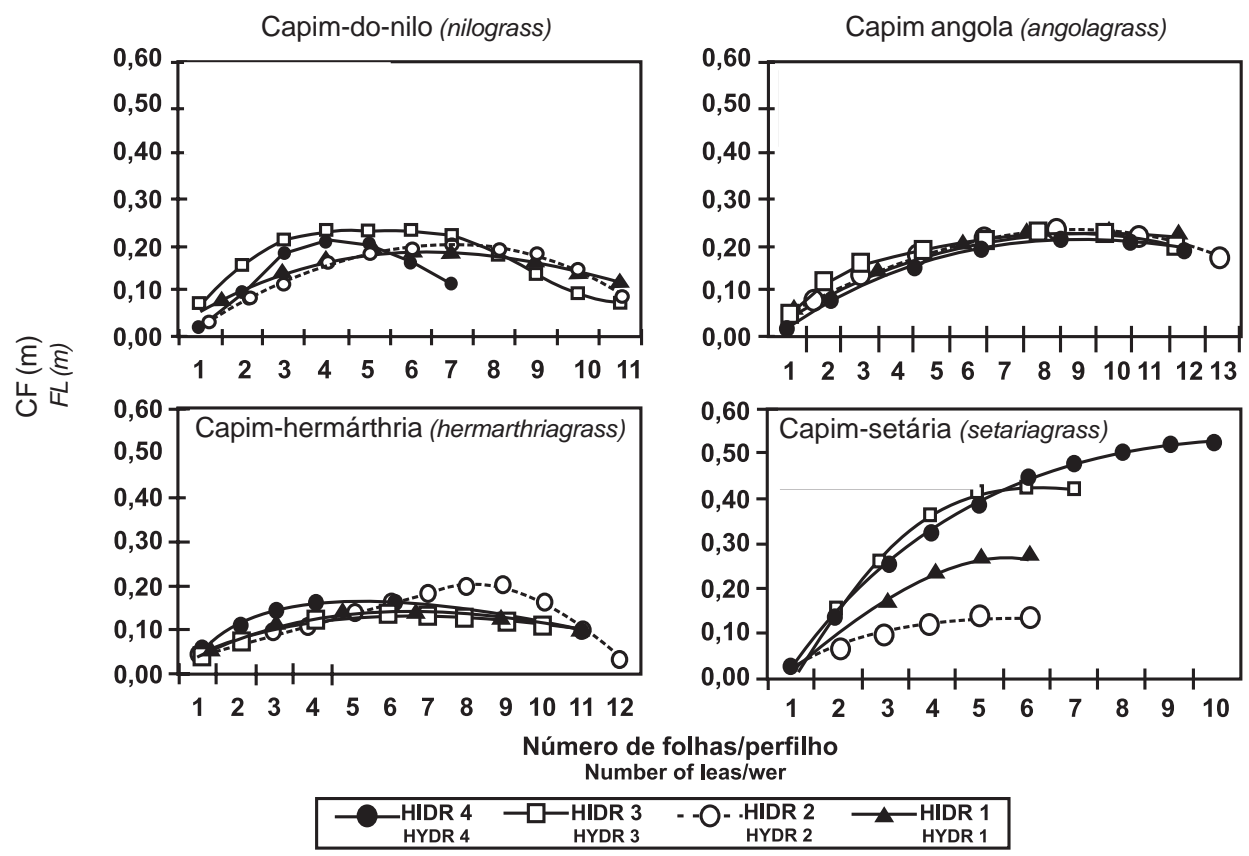

Figura 5 - Valores médios para o comprimento final de folhas individuais (CF, $m$ ) de quatro gramíneas tropicais, em função do nível hídrico do solo $(\mathrm{HIDR})^{1}$, a partir do aparecimento da primeira folha/perfilho.

Figure 5 - Mean values for final length of individual leaves ( $F L, m$ ) of four tropical grasses, according to the hydric level of soil (HYDR), since emergence of the first leaftiller.

1 Nível de saturação relativa da porosidade total do solo: HIDR 1 = 50\%; HIDR 2 = 100\%; HIDR 3 = 125\%; HIDR 4 = 150\%.

** Significativo a $1 \%$ pelo teste t.

1 Level of relative saturation of total soil porosity: HYDR $1=50 \% ; H Y D R 2=100 \% ; H Y D R 3=125 \% ; H Y D R 4=150 \%$.

** Significant at $1 \%$ of probability by Tukey test.

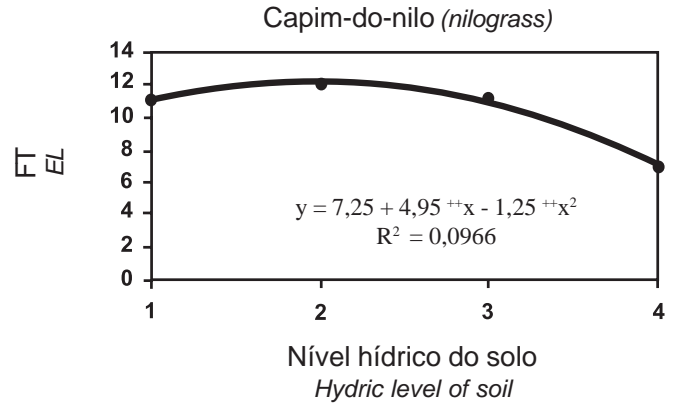

Capim-hermárthria (hermarthriagrass)

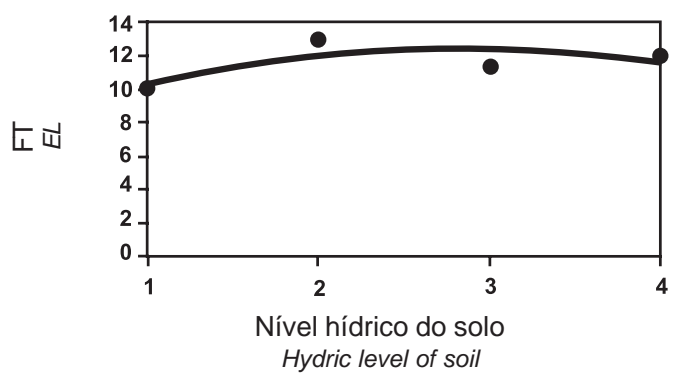

Capim-angola (angolagrass)

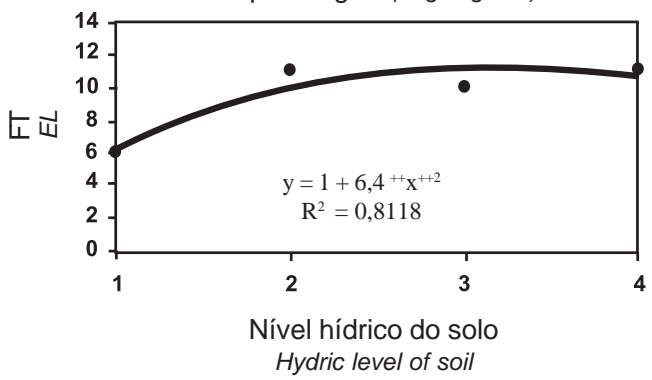

Capim-setária (setariagrass)

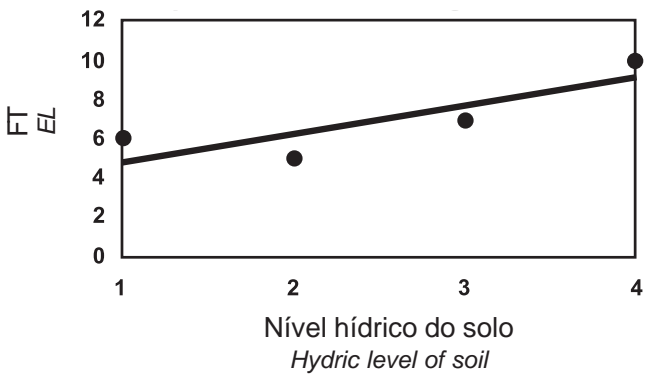

Figura 6 - Número total de folhas individuais expandidas por perfilho (FT, nº) de quatro gramíneas tropicais, em função do nível hídrico do solo (HIDR) ${ }^{1}$.

Figure 6 - Number of individual leaves expanded per tiller (LE, $\left.n^{\circ}\right)$ of four tropical grasses, according to hydric level of soil (HYDR).

1 Nível de saturação relativa da porosidade total do solo: HIDR 1 = 50\%; HIDR 2 = 100\%; HIDR 3 = 125\%; HIDR $4=150 \%$.

* Significativo a $5 \%$ pelo teste $\mathrm{t}$.

** Significativo a $1 \%$ pelo teste $\mathrm{t}$.

1 Level of relative saturation of total soil porosity: HYDR $1=50 \% ;$ HYDR $2=100 \% ;$ HYDR $3=125 \% ;$ HYDR $4=150 \%$.

* Significant at $5 \%$ of probability by Tukey test.

** Significant at $1 \%$ of probability by Tukey test. 
Capim-do-nilo (nilograss)

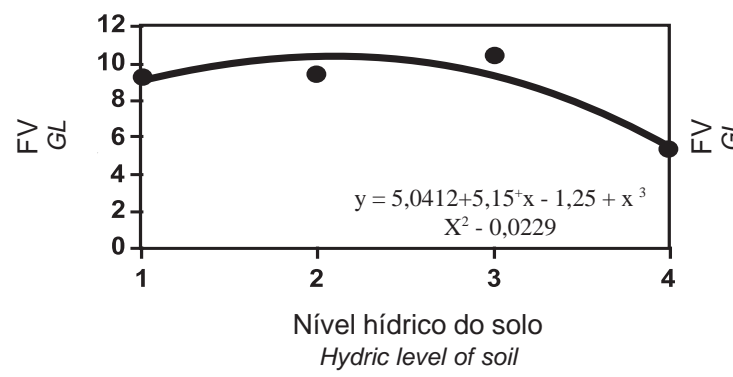

Capim-angola (angolagrass)

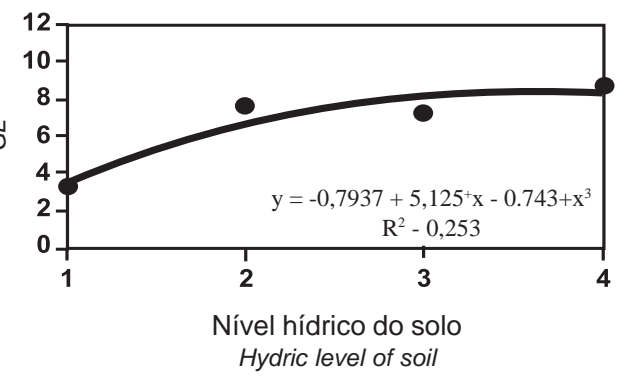

Capim-setária (setariagrass)
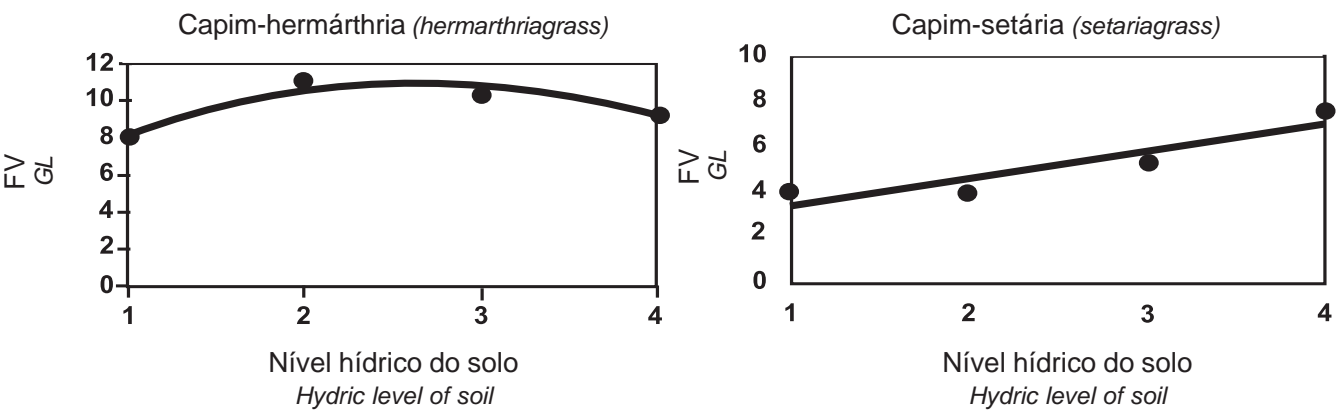

Figura 7 - Número total de folhas individuais verdes por perfilho (FV, n⿳-口) de quatro gramíneas tropicais, em função do nível hídrico do solo $(\mathrm{HIDR})^{1}$.

Figure 7 - Number of individual green leaves per tiller ( $L L, n^{\circ}$ ) of four tropical grasses, according to hydric level of soil (HYDR).

1 Nível de saturação relativa da porosidade total do solo: HIDR 1 = 50\%; HIDR 2 = 100\%; HIDR 3 = 125\%; HIDR 4 = 150\%.

* Significativo a $5 \%$ pelo teste $\mathrm{t}$.

** Significativo a $1 \%$ pelo teste $\mathrm{t}$.

1 Level of relative saturation of total soil porosity: HYDR $1=50 \% ; H Y D R 2=100 \% ; H Y D R 3=125 \% ; H Y D R 4=150 \%$.

* Significant at $5 \%$ of probability by Tukey test.

** Significant at $1 \%$ of probability by Tukey test.

o maior $(\mathrm{P}<0,05)$ número de folhas totais expandidas no período de avaliação. Segundo Fulkerson \& Slack (1995), o número de folhas vivas perfilho-1 é definido pela espécie, podendo-se esperar que plantas com melhores condições de aproveitamento dos fatores externos desejáveis (nutrientes, água, temperatura etc) atinjam o número máximo de folhas vivas por perfilho mais rapidamente.

\section{Conclusões}

O nível hídrico do solo influenciou o crescimento do capim-setária, que apresentou maiores taxas de alongamento foliar quando o solo estava acima da capacidade de saturação de água, além de boas características estruturais, como comprimento da folha e número de folhas vivas sob condições de alagamento do solo. Entretanto, o destaque do capimsetária sobre as demais gramíneas pode ter decorrido mais de suas características intrínsecas (porte elevado e tamanho das lâminas foliares) que das adaptativas ao alagamento.
Em condições de alagamento do solo, o capimhemárthria apresentou os melhores parâmetros morfogênicos, resultando em melhores características estruturais da planta, que lhe atribuem melhor desempenho sobre condições de seca e alagamento.

\section{Literatura Citada}

ARMSTRONG, W.; JUSTIN, S.H.F.W.; BECKETT, P.M. et al. Root adaptation to soil waterlogging. Aquatic Botany, v.39, p.57-73, 1991.

BARBOSA, R.A.; NASCIMENTO JR., D.; EUCLYDES, V.P.B. et al. Características morfogênicas e acúmulo de forragem de capim-tanzânia (Panicum maximum Jacq. Cv. Tanzânia) em dois resíduos forrageiros pós-pastejo. Revista Brasileira de Zootecnia, v.31, n.2, p.583-93, 2002.

BARUCH, Z. Responses to drought and flooding in tropical forage grasses. 1. Biomass allocation, leaf growth and mineral nutrients. Plant Soil, v.164, p.87-96, 1994a.

BARUCH, Z. Responses to drought and flooding in tropical forage grasses. 2. Leaf water potential, photosynthesis rate and alcohol dehydrogenase activity. Plant Soil, v.164, p.97105, 1994b.

BOTREL, M.A. Algumas considerações sobre gramíneas e leguminosas forrageiras. Coronel Pacheco, MG: EMBRAPA-CNPGL, 1983. 59p (Documentos, 9). 
CHAPMAN, D.F; LEMAIRE, G. Morphogenetic and structural determinants of regrowth after defoliation. In: INTERNATIONAL GRASSLAND CONGRESS, 17., 1993, New Zealand. Proceedings... New Zealand: s.ed., 1993. p.95-104.

CORSI, M.; BALSALOBRE, M.A.; SANTOS, P.M. et al. Bases para o estabelecimento do manejo de pastagem de Brachiaria. In: SIMPÓSIO SOBRE MANEJO DA PASTAGEM. PIRACICABA, 1994. Anais... Piracicaba: Fundação de Estudos Agrário “Luis de Queiroz”, 1994. p.249-66.

DESCHAMPS, F.C. Perfil fenológico de três ecotipos de capimelefante (Pennisetum purpureum, Schum.) In: REUNIÃO ANUAL DA SOCIEDADE BRASILEIRA DE ZOOTECNIA, 34., 1997, Juiz de Fora. Anais... Juiz de Fora: Sociedade Brasileira de Zootecnia, 1997. p.62-64.

FLARESSO, J.A.; SAIBRO, J.C. Tolerância ao alagamento de gramíneas forrageiras perenes de estação fria. Revista Brasileira de Zootecnia, v.20, n.6, p.632-37, 1991.

FULKERSON, W.J.; SLACK, K. Leaf number as criterion for determining defoliation time for Lolium perenne. 2. Effect of defoliation frequency and height. Grass and Forage Science, 50, n.1, p.16-20, 1995.

GARCEZ NETO, A.F.; NASCIMENTO JR., D.; REGAZZI, A.J. et al. Respostas morfogênicas e estruturais de Panicum maximum cv. Mombaça sob diferentes níveis de adubação nitrogenada e alturas de corte. Revista Brasileira de Zootecnia, v.31, n.5, p.1890-1900, 2002.

GOMIDE, J.A. Morfogênese e análise de crescimento de gramíneas tropicais. In: SIMPÓSIO INTERNACIONAL SOBRE A PRODUÇÃO ANIMAL EM PASTEJO, 1997, Viçosa, MG. Anais... Viçosa, MG: Universidade Federal de Viçosa, 1997. p.411-445.

JONES, C.A. The potential of Andropogon gayanus Kunth in the oxsols and ultisols savannas of tropical America. Herbage Abstract, v.49, p.1-8, 1979.

KIEHL, E.J. Manual de edafologia: relações solo-planta. São Paulo: Agronômica Ceres, 1979. 264p.

LANGER, R.H.M How grasses grow. London: Edward Arnold, 1972. 60p. (Studies in Biology, 34)

LEMAIRE, G.; CHAPMAN, D. Tissue flows in grazed plant communities. In: HODGSON, J.; ILLIUS, A.W. (Eds.). The ecology and management of grazing systems. New Zealand: CAB International, 1996. p.3-35.

LEMAIRE, G. The physiology of grass growth under grazing: tissue turnover. In: SIMPÓSIO INTERNACIONAL SOBRE PRODUÇÃO ANIMAL EM PASTEJO, 1997, Viçosa, MG. Anais...Viçosa, MG: Universidade Federal de Viçosa, 1997. p.115-144.
MIGLIETTA, F. Simulation of wheat ontogenesis. 1. Appearance of main stem leaves in the field. Climate Research, v.1, p.145-150, 1991.

MITIDIERI, J. Manual de gramíneas e leguminosas para pastos tropicais. 2.ed. São Paulo: Nobel, 1988. 162p.

NABINGER, C. Aspectos ecofisiológicos do manejo de pastagens e utilização de modelos como ferramenta e diagnóstico e identificação de necessidades de pesquisa. In: REUNIÃO DO GRUPO TÉCNICO REGIONAL DO CONE SUL (ZONA CAMPOS) EM MELHORAMENTOS E UTILIZAÇÃO DE RECURSOS FORRAGEIROS DAS ÁREAS TROPICAL E SUBTROPICAL, 1996, Porto Alegre. Anais... Porto Alegre: Universidade Federal do Rio Grande do Sul, 1996, p.17-62.

PINTO, J.C.; GOMIDE, J.A.; MAESTRI, M. Crescimento de folhas de gramíneas forrageiras tropicais, cultivadas em vasos, com duas doses de nitrogênio. Revista Brasileira de Zootecnia, v.23, n.3, p.327-32, 1994.

SKINNER, R.H.; NELSON, C.J. Elongation of the grass leaf and its relatioship to the phyllochron. Crop Science, v.35, p.4-10, 1995.

THOMAS, H. Analysis of the nitrogen response of leaf extension in Lolium temuletum seedings. Annals of Botany, v.51, n.3, p.363-371, 1983.

UNIVERSIDADE FEDERAL DE VIÇOSA - UFV. SAEG Sistema para análises estatísticas e genéticas. Versão 7.1. Viçosa, MG: 1997. 150p. (Manual do usuário)

VOLENEC, J.J.; NELSON, C.J. Responses of tall fescue leaf meristems to $\mathrm{N}$ fertilization and harvest frequency. Crop Science, v.23, p.720-724, 1983.

WERNER, J.C.; PAULINO, V.T.; CANTARELLA, H. et al. Recomendações de adubação e calagem para o Estado de São Paulo. 2.ed. Campinas: Instituto Agronômico de Campinas, 1986. p.263-73.

WILHELM, W.W.; McMASTES, G.S. Importance of the phyllochron in studying development and growth in grasses. Crop Science, v.35, n.1, p.1-3, 1995. 